\title{
Effect of tolazoline hydrochloride on sputum viscosity in cystic fibrosis
}

\author{
ELIZABETH A. FEATHER and GEORGE RUSSELL \\ Department of Child Health, University of Aberdeen, and the Royal Aberdeen Children's Hospital
}

Comparisons have been made between the effects of autonomic dysfunction and the pathophysiological changes in the exocrine secretions from patients with cystic fibrosis (Roberts, 1959). Cotton (1966) found that administration of tolazoline hydrochloride (an alpha-adrenergic blocker) to patients with cor pulmonale in the terminal stages of cystic fibrosis was associated with an improvement in the results of their lung function tests. This effect might have been due to an alteration of the abnormal viscosity of the bronchial mucus mediated via the autonomic nervous system, thus permitting easier expectoration. Measurement, by means of a Ferranti-Shirley cone and plate viscometer, of several different aspects of sputum viscosity is described. Tolazoline hydrochloride, administered to five patients with cystic fibrosis, was shown not to differ significantly from a placebo in its effect on sputum viscosity and dynamic lung volumes. We could not relate the improved lung function seen in Cotton's series to an autonomic effect of the drug on the physical properties of bronchial mucus in this condition.

The nature of the widespread disturbance of exocrine gland function in cystic fibrosis (CF) is not known (Shwachman, 1967), but abnormal viscosity of the secretions of the mucous glands has been held responsible for the clinical manifestations of the disease (Zuelzer and Newton, 1949).

Cotton (1966) treated patients who had severe lung disease due to CF with tolazoline hydrochloride, a vasodilator and alpha-adrenergic blocker, and found unexpected improvements in their pulmonary function tests. Tolazoline has been shown to reduce pulmonary hypertension in CF (Kelminson, Cotton, and Vogel, 1967). Whether the striking clinical improvement and prolongation of life achieved in Cotton's (1967) patients was due to reduction of pulmonary hypertension or to other factors is not known. An explanation might be provided by the finding of Kinnison, Breeden, Carmack, Ballard, Mel, and Hemingway (1965) that reduction of pulmonary arterial pressure in dogs increased the depth and rate of ventilation. The same effect, if it were to occur in patients with $\mathrm{CF}$, might promote bronchial drainage. Alternatively, in view of the evidence for disturbed autonomic function in CF (Farber, 1944; Bergstrand, 1951; Roberts, 1959), it is possible that the effect of tolazoline could be mediated by its alpha-adrenergic blocking action, possibly by an effect on the mucous glands of the respiratory tract where any lowering of sputum viscosity could be expected to reduce airways obstruction and allow re-expansion of collapsed areas.

There are many situations where disturbed autonomic nervous activity might explain the abnormalities of exocrine secretion found in CF. Roberts (1959) states that pancreatic histology in early cases of CF shows the picture of sustained oversecretion by serous glandular cells. The alterations in salivary gland secretion which occur in CF may be reproduced in part by the administration of methacholine to normal subjects (Chernick, 1968) and in patients with CF there is a partial correction of the abnormalities of submaxillary secretion following the administration of guanethidine (Chernick and Barbero, 1966). Andersen (1949) states that bronchial secretion in CF is viscous and may be abundant ; studies on organ cultures from human bronchial mucous glands have shown secretion to be stimulated by cholinergic drugs and to be inhibited by atropine (Reid, 1968). Other evidence for autonomic imbalance in CF was obtained by Rubin, Barbero, and Chernick (1966), who showed that the rate of dilatation following maximum constriction of the CF pupil was retarded and that the total dilatation was less than in healthy controls.

In view of these observations, the demonstration of change in the viscosity of bronchial secretions 
which could be attributed to tolazoline therapy might prove helpful in elucidating the basic abnormality in CF. We therefore studied the effect of treatment with tolazoline hydrochloride on simple tests of airways obstruction and on sputum viscosity in five patients with $\mathrm{CF}$.

\section{METHODS}

\section{PATIENTS}

A total of 30 patients with CF from the North, Northeastern, and Eastern Hospital Regions of Scotland were available, but only five were regularly able to produce sputum and all of these co-operated in the study. Age, sex, and forced vital capacity (FVC) expressed as a percentage of the predicted value for each patient at the start of the study are shown in Table I. The last measurement has been shown to

\section{T A B LE I}

CLINICAL DETAILS OF PATIENTS WITH CYSTIC FIBROSIS

\begin{tabular}{|c|c|c|c|c|}
\hline \multicolumn{2}{|c|}{ Patient } & \multirow{2}{*}{$\begin{array}{c}\text { Age (yr) } \\
7 \\
10 \\
6 \\
19 \\
15\end{array}$} & \multirow{2}{*}{$\begin{array}{l}\text { Sex } \\
\mathbf{M} \\
\mathbf{M} \\
\mathbf{F} \\
\mathbf{F} \\
\mathbf{M}\end{array}$} & \multirow{2}{*}{$\begin{array}{c}\begin{array}{c}\text { FVC as } \% \\
\text { predicted }\end{array} \\
37 \\
92 \\
80 \\
78 \\
36\end{array}$} \\
\hline $\begin{array}{l}1 . \\
2 . \\
3 . \\
4 . \\
5 .\end{array}$ & $\begin{array}{l}\text { H.C. } \\
\text { S.H. } \\
\text { G.G. } \\
\text { A.L. } \\
\text { C.H. }\end{array}$ & & & \\
\hline
\end{tabular}

correlate with an independent clinical and radiological grading in patients with CF (Mearns, 1968). Predicted values for FVC were obtained from Strang's data (1959) except for patient 3, where the height was below that of the smallest children in his series, and so Lunn's (1965) figures were used.

All patients were treated with pancreatin and antibiotics and three with physiotherapy in addition. Patients were studied during a clinically stable period of their illness and continued to receive their usual treatment under the supervision of their physicians.

TRIAL DESIGN Dummy tablets or tablets of tolazoline hydrochloride were administered orally for alternate seven-day periods. The procedure was then repeated so that each patient received two seven-day courses of both the placebo and tolazoline. The first two sevenday periods are referred to as 'fortnight I' and the second two seven-day periods are referred to as 'fortnight II'.

Tolazoline and placebo tablets of similar appearance and number were added to the patients' normal regimen. Because of the possibility of undesirable sideeffects, tablets were administered 'patient blind' and the dose was increased during the first three days of each period to reach the required dose of $2 \mathrm{mg}$. $/ \mathrm{kg}$. body weight by the third day. To avoid any "carry over' of the drug effect on the patient from one period to the next, only days 4 to 7 of each week were analysed statistically.
On days 4 to 7 , sputum samples were collected from each patient during the first hour after waking. Heart rates were measured with the patient at rest just before the measurement of static lung volumes on days 4 and 7. ECG changes looked for were peaking or increased amplitude of $\mathbf{P}$ waves, right ventricular hypertrophy, and right axis deviation, though we recognize that ECG evidence of pulmonary hypertension is unreliable (Goldring, Fishman, Turino, Cohen, Denning, and Andersen, 1964).

\section{PULMONARY FUNCTION TESTS}

These tests were recorded within one hour of sputum collection. Peak expiratory flow rate (PEF) was measured using a peak flow meter ${ }^{1}$. Forced expiratory volume in one second $\left(\mathrm{FEV}_{1}\right)$ and FVC were measured by means of a dry spirometer ${ }^{2}$, and results were expressed in millilitres corrected to B.T.P.S.

Narrowing of the airways by retained secretions is thought to contribute to respiratory obstruction in patients with CF. Most patients showed a variable degree of reversible airways obstruction which was probably due to oedema or bronchospasm. In an attempt to eliminate the component of airways obstruction due to oedema or bronchospasm, the largest volume obtained (whether before or after the inhalation of isoprenaline) was recorded. This value was termed the 'overall best volume' and usually occurred after the use of the bronchodilator: it was felt to be the value most likely to show changes due to elimination of retained secretions.

COLLECTION OF SPUTUM Sputum was collected on to a gauze grid (which allowed immediate separation of saliva and the least viscous part of the sputum) in airtight plastic containers. All samples were expectorated spontaneously and no patient was receiving mist tent or mucolytic therapy. Samples were sheared in duplicate within two hours of expectoration on a FerrantiShirley cone and plate viscometer, and all patients in the study co-operated fully.

Clinical observations showed that these children salivated profusely while coughing. During a preliminary study it was found that any attempt to measure sputum viscosity without prior removal of saliva gave totally unreproducible results. As it is not possible to obtain bronchial secretions which are not contaminated with saliva, we feel that this gauze grid method of separating saliva is probably as good as any.

MEASUREMENT OF SPUTUM VISCOSITY The theoretical aspects of measurement of sputum viscosity have been well described (Blanshard, 1955; Wells, Denton, and Merrill, 1961 ; Dippy and Davis, 1969). Sturgess (1969) has recently described the examination of the properties of $\mathrm{CF}$ sputum by means of a FerrantiShirley cone and plate viscometer. Briefly, viscosity

1Wright Peak Flow Meter, Airmed Ltd., Harlow, Essex 'Vitalograph, Vitalograph Ltd., Maids Moreton House, Buckingham 
may be defined as the tangential shearing force required to produce unit velocity gradient in a liquid.

$$
\begin{gathered}
\text { Viscosity } \\
\text { (in centipoises) }=
\end{gathered}
$$

Tangential shearing force per unit area (or shear stress) (in dynes $\left./ \mathrm{cm}^{2}\right) \times 100$

Velocity gradient (or shear rate in sec. $^{-1}$ )

In the apparatus used the sample is placed between the cone and plate. As the cone rotates the shear stress is measured as the torque exerted on the cone and the shear rate is derived from its angular velocity. For any given cone-plate viscometer, the viscosity of a sample is proportional to the ratio of the torque to the angular velocity. Many simple fluids exhibit Newtonian behaviour, shear stress and shear rate changing in direct proportion to one another so that the viscosity is independent of the rate of shear. Most biological fluids (such as blood, plasma, lymph, and mucus) do not show this constant viscosity at different shear rates and small concentrations of protein or high concentrations of suspended particles nullify the criteria of a Newtonian fluid (Wells et al., 1961). The apparent viscosity changes with the rate of shear and the length of time for which the sample has been sheared. Because of the differing viscosity under different conditions of shear there is no such thing as viscosity of a sputum sample. Instead, the term 'apparent viscosity' is used to denote the value recorded at a given shear rate. The viscometer used gave a gradual increase in shear rate from $0 \mathrm{sec}^{-1}$ to



FIGURE Idealized rheogram to illustrate the different aspects of viscosity measured. I, initial yield point; $Y$, yield value ; $T$, terminal yield point ; $S$, shear breakdown. $A$ is the point where the ratio of shear stress to shear rate represents the apparent viscosity at $900 \mathrm{sec}^{-1}$.
1,800 sec. $^{-1}$ followed by a deceleration over the same range. Rheograms were obtained showing the relation between shear rate and shear stress for each sputum sample. A typical rheogram is shown (Fig.).

To compare the viscosity of sputum before and after tolazoline therapy, five different rheological parameters were calculated for each sample.

ANALYSIS OF RHEOGRAMS For each sample the following values (defined below for the purpose of this study) were calculated:

(a) Apparent viscosity at $900 \mathrm{sec}^{-1}$ was measured during acceleration and expressed in centipoises.

(b) Initial yield point is the shear stress (in dynes/ $\mathrm{cm} .^{2}$ ) recorded where the best straight line through the lower half of the ascending limb of the rheogram from the value at 900 sec. $^{-1}$ intersects with the $X$ (shear stress) axis.

(c) Yield value is the shear stress (in dynes $/ \mathrm{cm}^{2}$ ) recorded on the ascending limb of the rheogram where the gradient first becomes maximal or reverses.

(d) Terminal yield point is the shear stress (in dynes $/ \mathrm{cm}^{2}$ ) recorded where the best straight line through the rheogram from $900 \mathrm{sec}^{-1}$ (on the decelerating limb) intersects with the shear stress axis.

(e) Shear breakdown is the difference in shear stress at $900 \mathrm{sec}^{-1}$ between the two limbs of the rheogram expressed as a percentage of the value on the ascending limb. The apparent viscosity at $900 \mathrm{sec}^{-1}$ during deceleration was usually less than that during acceleration due to breakdown of the structure during shearing. A decrease in viscosity with shearing is here expressed as positive shear breakdown and an increase as negative shear breakdown.

Apparent viscosity at $900 \mathrm{sec}^{-1}$, initial yield point and terminal yield point are as used by Palmer, Ballantyne, Diament, and Hamilton (1970). 'Yield value' here corresponds to 'static yield value', as used by Dippy and Davis (1969).

\section{RESULTS}

EFFECT OF TOLAZOLINE ON SPUTUM VISCOSITY Table II shows the effect of tolazoline on sputum viscosity. There was no significant difference in

T A B L E I I

EFFECT OF TOLAZOLINE THERAPY ON VISCOSITY OF SPUTUM

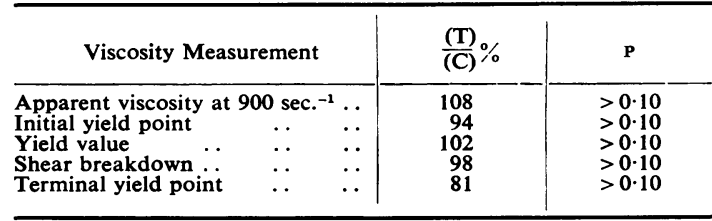

(T)

(C) $\%$ is the average viscosity measurement of sputum produced durins therapy with tolazoline, expressed as $\%$ of the average value during placebo theraby (5-patients). Non of the measures differed significantly from $100 \%$. 
viscosity between therapy with tolazoline and therapy with placebo.

EFFECT OF TOLAZOLINE ON PEF AND FEV Table III shows that there was no significant difference between therapy with tolazoline and therapy with placebo on the ventilation tests. Further analysis

\section{T A B L E I I I}

SUMMARY OF EFFECT OF TOLAZOLINE ON VENTILATION

\begin{tabular}{|c|c|c|c|c|}
\hline \multicolumn{3}{|c|}{ Measurements } & $\frac{(\mathrm{T})}{(\mathrm{C})} \%$ & $\mathbf{P}$ \\
\hline $\begin{array}{l}\text { Best peak flow rate } \\
\text { Overall best peak flow } \\
\text { Best FEV } \\
\text { Overall best FEV } \\
\text { Overall best FVC ... }\end{array}$ & $\begin{array}{l}\cdots \\
\cdots \\
\cdots \\
\cdots\end{array}$ & $\begin{array}{l}\ddot{ } \\
\ddot{*} \\
\ddot{*}\end{array}$ & $\begin{array}{l}96 \\
91 \\
92 \\
91 \\
93\end{array}$ & $\begin{aligned} & >0.10 \\
& =0.05 \\
& >0.10 \\
& >0.10 \\
0.1 & >\mathrm{P}>0.05\end{aligned}$ \\
\hline
\end{tabular}

$\frac{(T)}{(C)} \%=$ average value on tolazoline therapy ( 5 patients) expressed as a percentage of the average value on placebo therapy.

of the effect of tolazoline in patients 2 to 5 (as data on patient 1 were not complete) showed that the average best peak flow rate on tolazoline was $95 \%$ of the rate while on the placebo. This difference is not significant $(P>0 \cdot 10)$. Flow rates for different patients were, as would be expected, significantly different $(P<0.01)$. The difference between peak flow rates on days 4 and 7 under treatment was not significant $(0 \cdot 10>P>0 \cdot 05)$. The effect of tolazoline on best peak flow rate was independent of day or fortnight $(P>0 \cdot 10)$. Results for different days were independent of the fortnight $(\mathrm{P}>0 \cdot 10)$.

EFFECTS OF TOLAZOLINE ON PULSE RATE While patients received tolazoline their pulse rates were, on average, $15 \%$ higher than when taking a placebo; this difference was significant $(P<0.01)$. Pulse rates of patients were significantly different from one another $(P<0.01)$, as would be expected. The interaction between the drug and the patient was not significant $(P>0 \cdot 1)$, indicating that tolazoline increased the pulse rate of all patients.

SIDE-EFFECTS No side-effects attributable to therapy were noted by the patients.

\section{DISCUSSION}

There are several possible explanations for the fact that we were unable to demonstrate any significant effect of tolazoline on sputum viscosity or to confirm the improvement in pulmonary function demonstrated by Cotton (1966).

Owing to the difficulty of obtaining sputum, our patients were a highly selected group. Severity of pulmonary disease in the patients studied may well have been less than in the Denver cases where pulmonary hypertension (Cotton, 1967) was a prominent feature. None of the Aberdeen patients had clinical or ECG evidence of cor pulmonale, but this is known (Royce, 1951) to be a difficult diagnosis to make during life. Although normal subjects exposed to altitude are not at risk of developing pulmonary hypertension below 3,500 metres (Singh, Khanna, Lal, Hoon, and Rao, 1965), it is known that patients with obstructed airways can develop alveolar hypoventilation and significant increases in haematocrit at an altitude similar to that of Denver (Finley, Simson, and Lees, 1967). Similarly, it has been suggested that an excessive mortality rate from an increase in the incidence of cor pulmonale occurs in patients with obstructive pulmonary disease who live at a moderately elevated altitude (Renzetti, 1967). The effect of altitude in Denver (1,600 metres) may also have played a part in the hypoxia, pulmonary hypertension or response to tolazoline therapy in Cotton's cases.

Tolazoline was administered orally to our patients as it was felt that subjection of patients to the unpleasant effects of intravenous tolazoline in the absence of pulmonary hypertension would not have been justified. Grimson, Reardon, Marzoni, and Hendrix (1948) showed that tolazoline required longer to act when administered orally but that the total activity was similar to that when given intravenously. The dosage given was well within the range administered for pharmacological effect in other conditions and would be expected to affect bronchial secretion if this were to be altered as a result of adrenergic block. The finding that pulse rates while on tolazoline were significantly raised in all patients tends to confirm that the dosage used was sufficient to produce systemic effects and that absorption was satisfactory.

The number of patients was small but there was neither a significant improvement nor even a trend towards improvement during the period of tolazoline therapy.

It is possible that our periods of observation of the effect of tolazoline on sputum viscosity were too short. It may be that removal of inspissated secretions and the resultant improvements in pulmonary function tests required a longer period of time before a change was detectable and that during the period of observation new sputum was of decreased viscosity but was expectorated together with more highly viscous material. These investigations required considerable patient co-operation, and the possibility of performing more long- 
term studies without incidental changes in the clinical conditions of patients or change in their drug therapy seems remote.

We should like to thank Dr. K. N. V. Palmer for the use of the viscometer and for helpful advice. We should also like to thank the patients and their physicians for their co-operation, Dr. Gordon Hems for statistical help, and Professor R. G. Mitchell for reading the manuscript. Financial support was provided by the Cystic Fibrosis Research Foundation Trust.

\section{REFERENCES}

Andersen, D. H. (1949). Therapy and prognosis of fibrocystic disease of the pancreas. Pediatrics, 3, 406 .

Bergstrand, H. (1951). Fibrocystic disease of the pancreas, a disorder of the autonomic nervous system. Acta paediat. (Uppsala), 40,349 .

Blanshard, G. (1955). The viscometry of sputum. Arch. Middx Hosp., 5,222 .

Chernick, W. S. (1968). Pharmacological aspects of submaxillary gland secretion in cystic fibrosis. In Cystic Fibrosis, Ciba Foundation Group, No. 32, p. 28. Edited by Porter, R., and O'Connor, M. Churchill, London.

- and Barbero, G. J. (1966). Reversal of submaxillary salivary alterations in cystic fibrosis by guanethidine. In Cystic Fibrosis Club Abstracts, p. 5.

Cotton, E. K. (1966). Tolazoline in the treatment of cystic fibrosis. The Society for Pediatric Research, Program and Abstracts of the 36th Annual Meeting, p. 51

(1967). Personal communication.

Dippy, J. E., and Davis, S. S. (1969). Rheological assessment of mucolytic agents on sputum of chronic bronchitics. Thorax, 24, 707.

Farber, S. (1944). Pancreatic function and disease in early life. V. Pathologic changes associated with pancreatic insufficiency in early life. Arch. Path., 37, 238.

Finley, T., Simson, G., and Lees, M. M. (1967). Effect of high hematocrit states on ventilation at 5,316 feet. Amer. Rev. resp. Dis., $95,879$.

Goldring, R. M., Fishman, A. P., Turino, G. M., Cohen, H. I., Denning, C. R., and Andersen, D. H. (1964). Pulmonary hypertension and cor pulmonale in cystic fibrosis of the pancreas. J. Pediat., 65, 501 .
Grimson, K. S., Reardon, M. J., Marzoni, F. A., and Hendrix, J. P. (1948). The effects of Priscol (2-benzyl-4, 5-imidazoline hydrochloride) on peripheral vascular diseases, hypertension and circulation in patients. Ann. Surg., 127, 968.

Kelminson, L. L., Cotton, E. K., and Vogel, J. H. K. (1967). The reversibility of pulmonary hypertension in patients with cystic fibrosis. Pediatrics, 39, 24.

Kinnison, G. L., Breeden, C. J., Carmack, R. M., Ballard, B. M., Mel, P. J., and Hemingway, A. (1965). Reflex changes in heart rate and ventilation induced by central blood pressure changes. Amer.J. Physiol., 208, 1222.

Lunn, J. E. (1965). Respiratory measurements of 3,556 Sheffield schoolchildren. Brit. J. prev. soc. Med., 19, 115.

Mearns, M. B. (1968). Simple tests of ventilatory capacity in children with cystic fibrosis. Arch. Dis. Childh., 43, 528.

Palmer, K. N. V., Ballantyne, D., Diament, M. L., and Hamilton, W. F. D. (1970). The rheology of bronchitic sputum. Brit. J. Dis. Chest, in press.

Reid, L. (1968). Disturbances in the pattern of secretion of bronchial mucous glands. In Cystic Fibrosis. Ciba Foundation Study Group No. 32, p. 45, edited by Porter, R., and O'Connor, M. Churchill, London.

Renzetti, A., Jr. (1967). Veterans Administration Cooperative study: Mortality in relation to pulmonary function in chronic airways obstruction. Amer. Rev. resp. Dis., 95, 893.

Roberts, G. B. S. (1959). Fundamental defect in fibrocystic disease of the pancreas. Lancet, 2,964

Royce, S. W. (1951). Cor pulmonale in infancy and early childhood: report on 34 special patients with special reference to the occurrence of pulmonary heart disease in cystic fibrosis of the pancreas. Pediatrics, 8, 255.

Rubin, L. S., Barbero, G. J., and Chernick, W. (1966). Pupillary dysfunction as a concomitant of cystic fibrosis. Pediatrics, 38, 865 .

Shwachman, H. (1967). Cystic fibrosis. In Disorders of the Respiratory Tract in Children, edited by Kendig, E. L., Jr., p. 541. Saunders Philadelphia.

Singh, I., Khanna, P. K., Lal, M., Hoon, R. S., and Rao, B. D. P. (1965). High altitude pulmonary hypertension. Lancet, 2, 146.

Strang, L. B. (1959). The ventilatory capacity of normal children. Thorax, 14, 305.

Sturgess, J. (1969). A new pattern of sputum viscosity. Proceedings of the 5th International Cystic Fibrosis Conference, Cambridge, 1969, ed. Lawson, D., p. $3 \in 8$.

Wells, R. E., Denton, R., and Merrill, E. W. (1961). Measurement of viscosity of biologic fluids by cone plate viscometer. J. Lab. clin. Med., 57, 646.

Zuelzer, W. W. and Newton, W. A. (1949). The pathogenesis of fibrocystic disease of the pancreas. A study of 36 cases with special reference to the pulmonary lesions. Pediatrics, 4, 53. 